\title{
Terral de Vicuña, a Foehnlike Wind in Semiarid Northern Chile: Meteorological Aspects and Implications for the Fulfillment of Chill Requirements in Deciduous Fruit Trees $\mathscr{A}$
}

\author{
CARLO MONTES \\ NASA Goddard Institute for Space Studies, New York, New York \\ José A. RutLlANT \\ Centro de Estudios Avanzados en Zonas Áridas, Consorcio: Universidad de La Serena, Instituto de \\ Investigaciones Agropecuarias Intihuasi, Universidad Católica del Norte, Coquimbo, and \\ Departamento de Geofísica, Universidad de Chile, Santiago, Chile \\ ANitA Aguirre \\ Facultad de Agronomía, Universidad de Aconcagua, La Serena, Chile \\ LUISA BASCUÑÁN-GODOY AND CRISTÓBAL JULIÁ \\ Centro de Estudios Avanzados en Zonas Áridas, Consorcio: Universidad de La Serena, Instituto de \\ Investigaciones Agropecuarias Intihuasi, Universidad Católica del Norte, Coquimbo, Chile
}

(Manuscript received 1 October 2015, in final form 7 March 2016)

\begin{abstract}
The terral de Vicuña is a warm and dry wind that flows down the Elqui Valley in north-central Chile typically at dawn and early morning. Given that most terral episodes occur in austral winter when chill accumulation by deciduous fruit trees proceeds, negative effects on agriculture may be expected. During 11 (2004-14) winters a meteorological characterization of terral winds and the assessment of their impact on chill accumulation, by the modified Utah Model and the Dynamic Model, were performed. Within this period, 67 terral days (TD) were identified as those in which nighttime to early morning wind direction and speed, air temperature, and relative humidity reached defined thresholds on an hourly basis (terral hours). Most frequent TD featured 6-9 consecutive terral hours; duration is considered here as a proxy for their intensity. Synoptic-scale meteorological analysis shows that $65 \%$ of moderate and strong terral events develop as a cold, migratory anticyclone drifts poleward of the study area, coinciding with the onset of a midtropospheric ridge over central Chile, bringing southwest winds on top of the Andes ( $~ 500-h P a ~ l e v e l)$. The remaining $35 \%$ are either associated with $500-\mathrm{hPa}$ easterlies (foehn like), with prefrontal conditions ahead of a trough driving northwest 500-hPa winds, or with transitional 500-hPa westerlies. Assessments of chill accumulation during TD show that, although present average and cold winter conditions do not represent a major TD hazard to local agriculture, lower chill accumulation associated with anomalously high nocturnal temperatures could be significantly more important during present and future warmer winters.
\end{abstract}

Supplemental information related to this paper is available at the Journals Online website: http://dx.doi.org/10.1175/ JAMC-D-15-0275.s1.

Corresponding author address: J. A. Rutllant, Raúl Bitrán 1305, Colina El Pino, La Serena, Chile.

E-mail: jose.rutllant@ceaza.cl

\section{Introduction}

The Elqui Valley, in north-central Chile, is a complexterrain narrow catchment extending from the Pacific Ocean to the Andes Cordillera (Fig. 1). Its geographic location $\left(\sim 30^{\circ} \mathrm{S}\right)$ corresponds to a transitional semiarid zone between the southern margin of the hyperarid Atacama Desert to the north and the Mediterranean-type

DOI: 10.1175/JAMC-D-15-0275.1 


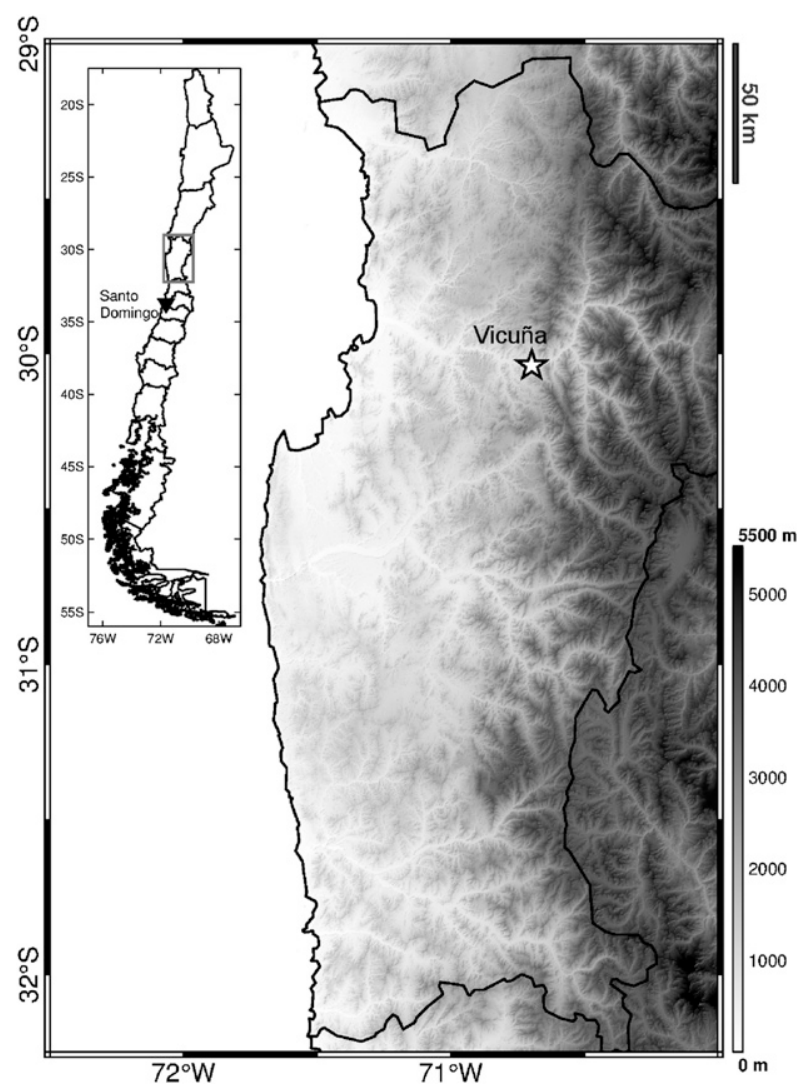

FIG. 1. Elevation map (m MSL) and location of the Coquimbo region in north-central Chile. The white star sign shows the meteorological measurements site (Vicuña) in the Elqui Valley, and black lines are administrative divisions. The location of the Santo Domingo radiosounding site is also shown.

climate region to the south. Its low annual mean precipitation $\left(\sim 100 \mathrm{~mm} \mathrm{yr}^{-1}\right)$ and seasonal variability are strongly controlled by the influence of the subtropical anticyclone of the southeastern Pacific (e.g., Garreaud and Aceituno 2007). At interannual and intraseasonal scales, the precipitation regime is strongly modulated by El NiñoSouthern Oscillation (ENSO) and the Madden-Julian oscillation, respectively (Montecinos and Aceituno 2003; Juliá et al. 2012). The complex orography of the Elqui basin produces important spatial variability in precipitation and other microclimatic features such as air moisture driven by low-level land-sea breezes (Kalthoff et al. 2006; Montes et al. 2010).

In addition to the aforementioned local climate features, the occasional occurrence of a warm and very dry nocturnal wind, locally known as terral de Vicuña (hereinafter the terral), is observed inland. This wind, generically and historically considered as a foehnlike wind, is an easterly down-valley warm and dry gusty wind that generally appears at night and extends into dawn and early morning, with speeds often above $2 \mathrm{~m} \mathrm{~s}^{-1}$.
These speeds can reach intermittently up to $8-10 \mathrm{~m} \mathrm{~s}^{-1}$ in about 2-h intervals, with associated low relative humidity $(\sim 10 \%)$ and high temperatures $\left(\sim 25^{\circ} \mathrm{C}\right.$; Puccio 1976). Although the terral can appear any time during the year, it is a typical feature of the cold season (austral winter); shelter air temperature can exceed $25^{\circ} \mathrm{C}$ at dawn when a terral occurs. These terral events often occur in consecutive days, synchronized with the diurnal cycle of mountain-valley breezes. Similar to the terral, strong downslope winds have been observed and described in other Chilean valleys, such as the raco wind in the upper Maipo Valley $\left(\sim 33.5^{\circ} \mathrm{S}\right.$; Rutllant and Garreaud 2004) and the puelche wind farther south (Miller 1976; Inzunza 2009). A number of societal impacts are reported during the occurrence of these strong descending winds over mountain regions, which vary depending on where they occur. For instance, strong air pollution episodes in the cold season are driven by the raco wind in central Chile after the strengthening and sinking of the subsidence inversion by the descending winds (Rutllant and Garreaud 2004). Similarly, puelche winds favor the occurrence and propagation of forest fires in the warm/dry season (Inzunza 2009). Material damages and effects on human welfare resulting from this type of windstorm have also been reported for North America (Brinkmann 1974; Cao and Fovell 2015) and Europe (Reid and Turner 1997). At the other (east) side of the Andes, Norte (2015) reports strong negative local impacts by the zonda wind as a result of the wind strength and warm/dry air conditions. Among the latter, mechanical and physiological damage to fruit trees during flowering (Caretta et al. 2004), together with a higher probability of frost exposure by accelerating the blooming rate due to a higher zonda wind frequency in spring (Antico et al. 2016), can potentially affect fruit quality and production.

The Elqui Valley is an economically important subtropical agricultural area where, despite the severe water scarcity, the successful establishment of Mediterraneantype agriculture is possible because of irrigation infrastructure and technology, along with well-adapted cultivation techniques. Agriculture in the inland areas of the valley is known for the climate-driven early production of deciduous fruit trees such as walnut and peach, as well as other crops such as grapes and blueberries. As for most temperate deciduous trees, the fulfillment of chilling requirements during the cold season (austral winter) is necessary to ensure homogeneous release of dormancy (Charrier et al. 2011). In this sense, insufficient winter chill can cause an erratic and uneven breaking of buds, a spread out of flowering, and poor yield performance, which has been reported for warm winter climates (Luedeling 2012; Atkinson et al. 2013). This is the case for the Elqui Valley, where shorter and warmer winters 
impose the need for using dormancy-breaking chemicals (i.e., hydrogen cyanamide) to compensate for the deficit in winter chilling (Reginato et al. 1994). Here, disorders in the budbreak and reduced depth of endodormancy on grapevines have been associated with higher daily winter temperatures, as compared with more temperate winters in the Maipo Valley (Perez et al. 2007). The latter raises the question about how the effect of higher air temperatures at nighttime and dawn that occur during terral events, together with their frequency and duration, superimposed on the existing warmer conditions in relation to agricultural areas farther south, represents a potential hazard for the fulfillment of chilling requirements in deciduous fruit trees. Consequently, with the aim of further understanding the local climate features, the main goal of this study is to characterize the local meteorological aspects and synoptic drivers associated with terral events and the assessment of their implications for winter-chill accumulation in the central part of the Elqui Valley.

\section{Study site, data, and methods}

\section{a. Study site}

The study was carried out in the Elqui Valley of northcentral Chile, and specifically in the city of Vicuña. Vicuña, located at the foot of the Andes in the mid-toupper section of the valley (Fig. 1), corresponds to an agricultural area surrounded by hills with narrow plains along the mainstream and tributaries of the Elqui River, where agriculture develops. Crops, fruit trees, and vineyards, which cover about $160 \mathrm{~km}^{2}$, are cultivated mostly along the bottom of the valley, where irrigation is a widespread practice. Vicuña's main climatic features include mostly clear skies, a low afternoon relative humidity of $\sim 25 \%$ on average, and minimum (maximum) air temperatures ranging from $4^{\circ}\left(21^{\circ}\right)$ to $10^{\circ} \mathrm{C}\left(29^{\circ} \mathrm{C}\right)$ between winter and summer. These features contrast with the colder and more humid coastal areas, as a result of a strong along-valley gradient in climate imposed by the complex topography (Kalthoff et al. 2006). In addition, precipitation in the Elqui Valley, whose axis runs approximately east-west, falls mostly during the winter months, when midlatitude, synoptic-scale disturbances reach the study area (Falvey and Garreaud 2007), accumulating an annual average of $90 \mathrm{~mm}$ at the coast, $100 \mathrm{~mm}$ in Vicuña, and near $200 \mathrm{~mm}$ in the upper basin $(\sim 3000 \mathrm{~m}$ MSL).

\section{b. Datasets}

In situ meteorological data were obtained from an automatic weather station located at the Intihuasi Experimental Center of the Instituto de Investigaciones Agropecuarias (INIA) in the city of Vicuña $\left(30.03^{\circ} \mathrm{S}\right.$, $70.69^{\circ}$ W; Fig. 1), operated by the Center for Advanced Studies in Arid Zones (CEAZA). These data consist of hourly time series of air temperature and relative humidity measured at $1.5 \mathrm{~m}$, together with wind speed and direction measured at $2 \mathrm{~m}$ above ground, available for the period of 2004-14. Given that previous studies (e.g., Puccio 1976) and local knowledge suggest that terrals predominantly occur in austral winter, data series were restricted to the period between 1 April and 31 August, which coincides with the period of chill accumulation before budbreak (Montes et al. 2010). Along with these observations, data from the National Centers for Environmental Prediction (NCEP) Final (FNL) Operational Model Global Tropospheric Analyses (NOAA/NCEP 2000; available online at http://rda.ucar.edu/datasets/ ds083.2/) were used to characterize the atmospheric circulation patterns associated with terral events (section 2d). Data correspond to 1200 UTC [0800 local time (LT)] midtropospheric 500-hPa geopotential height and sea level pressure (SLP), together with zonal and meridional wind components at the respective levels. In addition, upper-air data from the Santo Domingo, Chile, radiosonde station $\left(33.65^{\circ} \mathrm{S}, 71.61^{\circ} \mathrm{W}\right.$; Fig. 1$)$, available online through the University of Wyoming archive (http://www.weather.uwyo.edu/upperair/sounding.html), were considered (section 2d).

\section{c. Defining terral episodes}

The terral de Vicuña can be roughly defined as a warm, dry, down-valley (westward) wind preferentially blowing at nighttime and dawn during winter months. First, to meet this general description, terral hours were defined as those hours in which the hourly averaged wind direction $W_{D}$, wind speed $W_{S}$, air temperature $T$, and relative humidity $\mathrm{RH}$ respectively fulfill the following simultaneous thresholds at the Vicuña meteorological station: $W_{D}$ from $360^{\circ}$ to $180^{\circ}$ (the two eastern quadrants), $W_{S}>2 \mathrm{~m} \mathrm{~s}^{-1}, T>11^{\circ} \mathrm{C}$, and $\mathrm{RH}<30 \%$.

After isolating terral hours, terral days (TD) were defined as those featuring one or more consecutive terral hours. Moreover, the mild winter conditions and the typical radiative-driven upslope breeze suggest that the effect of terral on chill accumulation during daytime is not expected to be significant so that TD starting between 0800 and $0000 \mathrm{LT}$ (UTC $-4 \mathrm{~h}$ ) were removed from the analysis. As a last step, single terral events (TE) were defined as those TD lasting for one or more consecutive calendar days.

\section{d. Synoptic-scale meteorological characterization of $T E$}

After identifying TE occurrences during the study period, a first classification of the attending synoptic weather conditions for each of them was based on results 
from Rutllant and Garreaud (2004), given the regional nature of strong downslope flow occurrences in central Chile $\left(31.5^{\circ}-34.5^{\circ} \mathrm{S}\right)$. As in the referenced study, Santo Domingo radiosonde data, with observations at 0000 and 1200 UTC (2000 and 0800 LT, respectively) were considered to be representative of the synoptic-scale weather conditions over central Chile. Second, these authors identify two main synoptic-scale meteorological configurations, one that corresponds to an incoming ridge in the midtroposphere and associated coastal low convergence in lower levels (their postfrontal group A), featuring southwest winds in the mid-to-upper troposphere, and a second that corresponds to an incoming trough in the midtroposphere and associated prefrontal near-surface convergence (their prefrontal group B), with northwest winds aloft. Therefore 500-hPa (representing airflow over the mean Andes top) wind directions from the Santo Domingo radiosonde data at 1200 UTC (0800 LT) were considered. After sorting out and grouping wind directions at $500 \mathrm{hPa}$, composites of 500-hPa geopotential heights and wind vectors, along with the SLP field and surface $(10 \mathrm{~m})$ winds, were obtained for each 500-hPa wind direction group.

\section{e. Winter-chill models}

Dormancy release and budburst occurrence in deciduous fruit trees require the exposure of plant structures to a certain period of low temperatures depending on the species and variety. The meeting of these chilling requirements is dependent, among other factors, on the lower and upper thresholds in temperatures and on the magnitude of the contribution of different temperature ranges (Cesaraccio et al. 2004). A number of models to quantify winter-chill accumulation have been developed, which can vary in complexity from the simple Chilling Hours Model of Weinberger (1950), which considers the cumulative number of hours below $7^{\circ} \mathrm{C}$ to predict budburst, to the Utah Model of Richardson et al. (1974), which introduces the concept of chill units (CU) as the weighted temperatures according to their effectiveness in breaking dormancy, accounting for the negation effect of high temperatures on previously accumulated chill. Other classical models that are based on CU include the North Carolina Model (Shaltout and Unrath 1983) and the Positive Utah Model (LinsleyNoakes and Allan 1994). A more accurate model was subsequently developed by Fishman et al. (1987a,b), the Dynamic Model, which uses as a first step an approach that is similar to the CU approach in terms of considering both the optimal range and the negative influence of high temperatures on chill effectiveness to produce a thermally labile precursor of an active dormancy-breaking factor. These results are then transferred into chill portions (CP) that cannot be broken down by high temperatures. Although comparative studies have shown that the Dynamic Model is the most robust in estimating chill requirements in fruit trees (e.g., Luedeling et al. 2009a; Zhang and Taylor 2011; Ghrab et al. 2014), its more complex implementation has prevented its widespread use and thus CU-based approaches are still preferred. Campoy et al. (2011) stress that most current chilling models are largely empirically based and therefore further comprehension of physiological processes is still necessary. For these reasons, use of these models should be complemented with site and experimental information.

Here, two chill models have been used and contrasted to assess the influence of terral events on winter-chill accumulation. First, CU were estimated by using a more accurate version of the Utah Model, known as the modified Utah Model of Linvill (1990), which is presented in appendix A. This model corresponds to a continuous-function version of the original Utah Model of Richardson et al. (1974) and has been previously used for chill accumulation assessment under changing climate conditions in various agricultural regions worldwide (e.g., Hennessy and Clayton-Greene 1995; Darbyshire et al. 2011). In a second step, CP were calculated by using the Dynamic Model of Fishman et al. (1987a,b), which has been reported as better adapted to mild winter climates (Erez et al. 1990). The Dynamic Model uses a different approach to determine chill accumulation and dormancy completion. This model assumes that chill accumulation is a two-step process, the first being the low-temperature-driven synthesis of an intermediate product that is then able to be destroyed by high temperatures in the second step. The dynamics of the model is described by the Arrhenius law for the temperature dependence of chemical reactions. Once this precursor reaches a threshold concentration, it is stored as a CP. The CP calculation procedure is detailed in appendix B. An example on how these two chill models operate to estimate winter chill under contrasting temperature conditions is provided in the online supplementary material, along with some reference values from the literature regarding $\mathrm{CP}$ and $\mathrm{CU}$ in their capacity to fulfill winter-chill requirements in species of importance in Mediterranean and semiarid climates (supplemental Table S1).

Both the modified Utah Model and the Dynamic Model were applied using hourly temperatures $\left({ }^{\circ} \mathrm{C}\right)$ as input for the period spanning 1 April and 31 August. In our case, April has been included on the basis of the observed onset of chill accumulation according to the previously described models for the Vicuña meteorological data, although this onset month has been taken as March in 
Miranda et al. (2013) or May in Darbyshire et al. (2011) and Zhang and Taylor (2011).

\section{Results and discussion}

\section{a. Meteorological aspects of terral winds}

\section{1) LOCAL FEATURES}

The application of the criteria for defining terral hours resulted in a total of $67 \mathrm{TD}$ throughout the eleven 5-month austral winter periods (April-August 2004-14), averaging $6 \mathrm{TD}$ per winter (return period of 1 every 3.3 weeks; Fig. S3 of the online supplemental material). Figure 2 shows that the distribution of number of cases and duration/intensity of TD roughly follows a close-tonormal shape, with a mode in the 6-9-h range accumulating near $55 \%$ of TD. This more frequent intensity range has been named "moderate," leaving a "weak" intensity range in the $1-5$-h range ( $18 \%$ of TD) and a "strong" intensity range from 10 or more hours $(27 \%$ of TD). TE typically last 1 day (40 TE; 76\%), and less frequently 2 days ( $9 \mathrm{TE} ; 18 \%$ ) and 3 days ( $3 \mathrm{TE} ; 6 \%$ ).

When comparing long-lasting (3-4 days) raco events in the Maipo Valley, representing 20\% of the cases there (Rutllant and Garreaud 2004), with only $6 \%$ of 3-day TE here (500 km farther north), it becomes evident that midlatitude synoptic weather disturbances in central Chile only marginally or occasionally reach north-central Chile, representing here a short transient phenomenon.

The average diurnal cycles of air temperature, relative humidity, wind speed, and direction at Vicuña for the three TD-intensity ranges, in addition to those that do not qualify as TD (labeled as Non-TD), are presented in Fig. 3. Non-TD follow typical diurnal cycles of radiatively driven inland valley climate regimes. Figure $3 \mathrm{a}$ shows the abrupt nocturnal increase in air temperature as a most remarkable feature during TD that suppresses the characteristic nocturnal surface cooling (e.g., Whiteman et al. 2004), likely as a result of the downslope adiabatically warmed air being advected and mixed downward by the strong winds (Fig. 3c). As expected, solar radiation absorption in the morning raises dawn air temperature almost independent of the TD intensity, reaching similar maxima around 1500 LT. Accordingly, relative humidity (Fig. 3b), experiences a large nocturnal decrease, leveling in the early morning $(\sim 0600 \mathrm{LT})$ to values close to $10 \%$, irrespective of the strength of the TD. Strong differences in the nighttime and early morning wind speed (Fig. 3c) are observed for the three intensity ranges, with mean maximum values exceeding $5 \mathrm{~m} \mathrm{~s}^{-1}$ for the strongest TD. As for the average diurnal

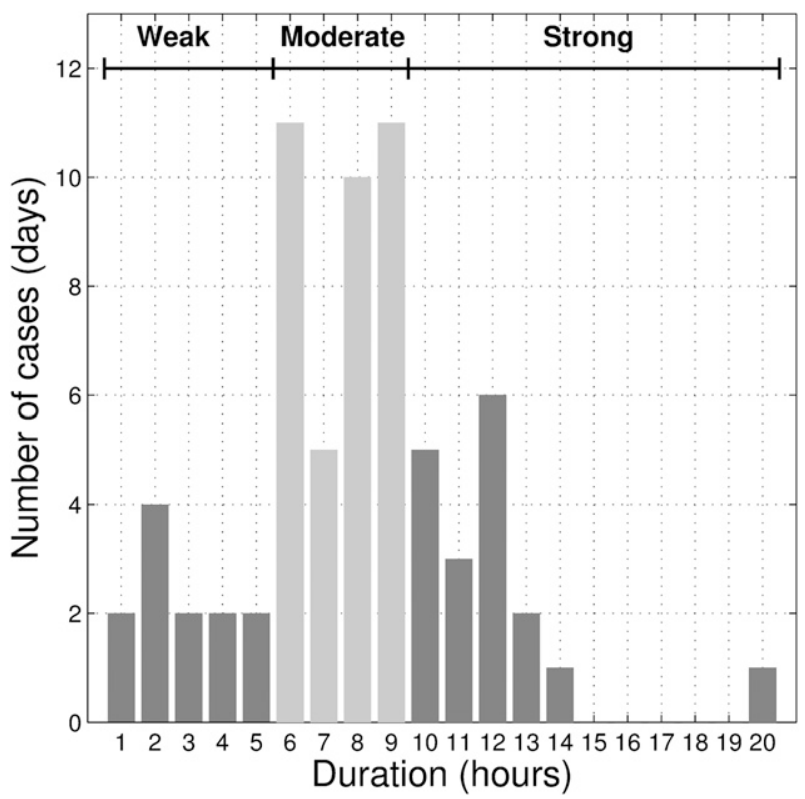

FIG. 2. Frequency distribution of TD duration/intensity in hours and selected intensity ranges.

cycle in wind direction (Fig. 3d), the duration of the easterly (downvalley) winds closely follows TD intensities.

A different presentation of the wind behavior at Vicuña is illustrated by the wind roses in Fig. 4 for the entire dataset (Fig. 4a) and for TD only (Fig. 4b). The all-data wind distribution (Fig. 4a) depicts a regular valley-mountain breeze regime along the valley axis (e.g., Kalthoff et al. 2002). The overwhelming persistence and higher speed of the downvalley winds during TD prevent the appearance of the daytime wind directions in Fig. $4 \mathrm{~b}$.

\section{2) SYNOPTIC-SCALE METEOROLOGICAL CHARACTERIZATION}

To focus on the synoptic-scale meteorological analysis in cases with a higher potential impact on chill requirements, as evidenced from Fig. 3a, the classification was performed only for the 55 moderate and strong TD.

The grouping of wind directions on top of the Andes (i.e., 500-hPa level) led to the following four categories: southwest winds (type A), west winds (type T: transition conditions), southeast winds (type F: foehnlike conditions), and northwest winds (type B: incoming trough). Skew $T$ diagrams representing the Santo Domingo radiosonde data for selected dates, illustrating typical conditions for each of the four wind direction categories, are presented in Fig. 5 and are described as follows. A dominant southwesterly wind direction characterizes 

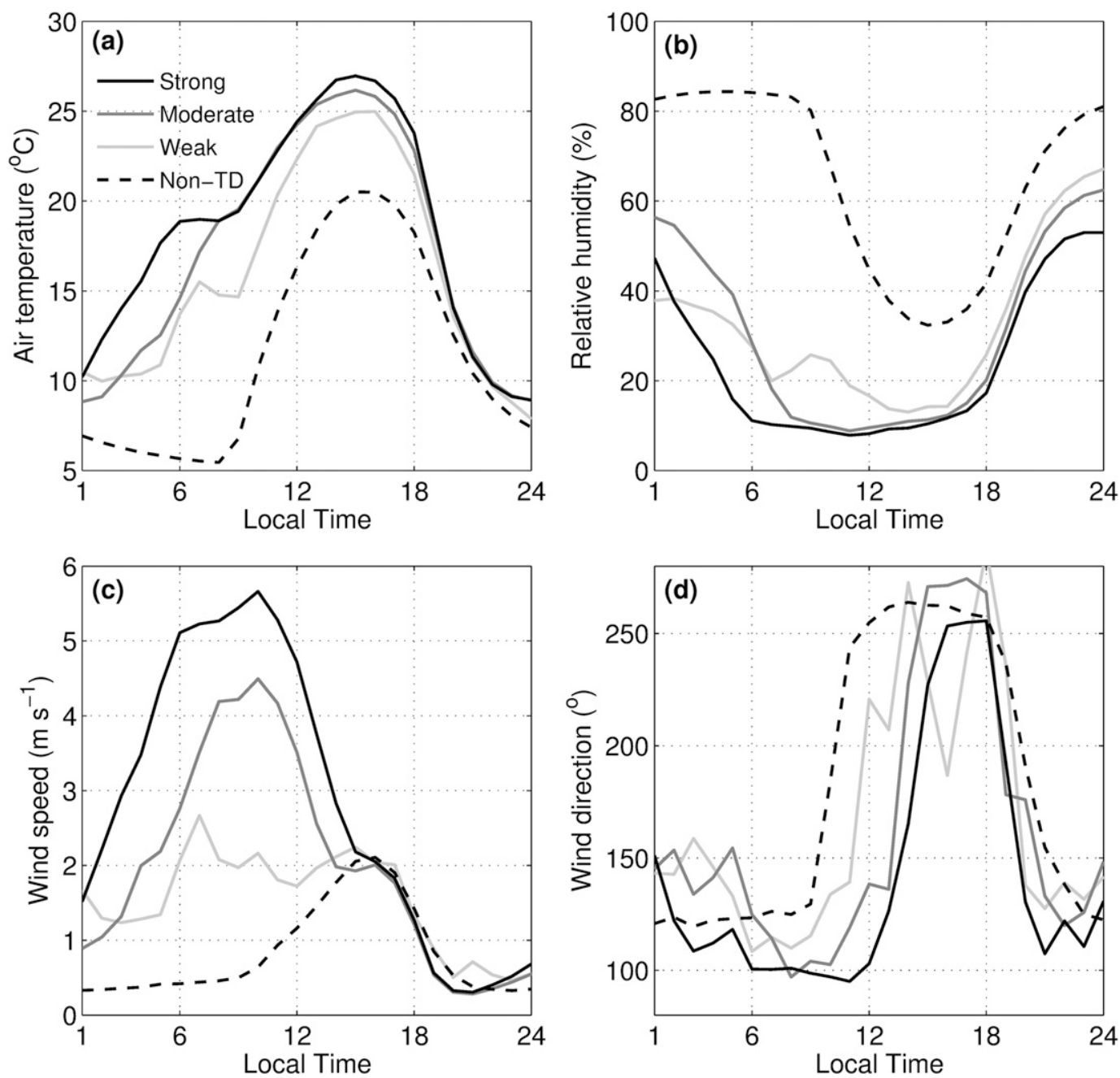

FIG. 3. Average diurnal cycles of (a) air temperature, (b) relative humidity, (c) wind speed, and (d) wind direction for strong, moderate, and weak TD and for non-TD.

type-A wind profiles from the mid-to-upper troposphere, whereas zonal wind components change from easterlies in the lower troposphere up to $600-700 \mathrm{hPa}$ to westerlies aloft. Transitional (type T) wind profiles exhibit stronger westerly winds in the upper half of the troposphere, with a shallow surface layer of easterlies. Here the dryness of the lower troposphere contrasts with moist conditions above $500 \mathrm{hPa}$. Similar to type A, southerly meridional wind components prevail in the upper half of the troposphere in type-F cases, but now with a deeper layer of easterly wind components extending from the surface up to and beyond the Andes mean top. Conversely, type-B cases show northwesterly winds throughout the troposphere, except for a thin surface layer with easterlies. General features in all four groups include a surface or near-surface subsidence temperature inversion base at Santo Domingo, in connection with the adiabatically warmed downslope easterlies.
Composites of midtropospheric and surface circulation associated with the four synoptic patterns are presented in Fig. 6. The type-A composite ( $65 \%$ of TE; Fig. $6 a)$ shows a general southwest flow at $500 \mathrm{hPa}$, corresponding to an incoming ridge in the midtroposphere that is associated with postfrontal conditions. On the other hand, surface circulation (Fig. 6b) shows a migratory high pressure system crossing the southern Andes, geostrophically generating easterly wind components at the lower levels of the atmosphere that converge toward the leading edge of the attending coastal low (Garreaud et al. 2002), as also observed in Fig. 5a. This type-A weather pattern coincides with the most frequent raco wind pattern in Rutllant and Garreaud (2004) and with a high associated frost risk in central Chile (Montes et al. 2013).

For the remaining $35 \%$ of cases, $18 \%$ are classified as transition conditions (type T) between well-defined, 


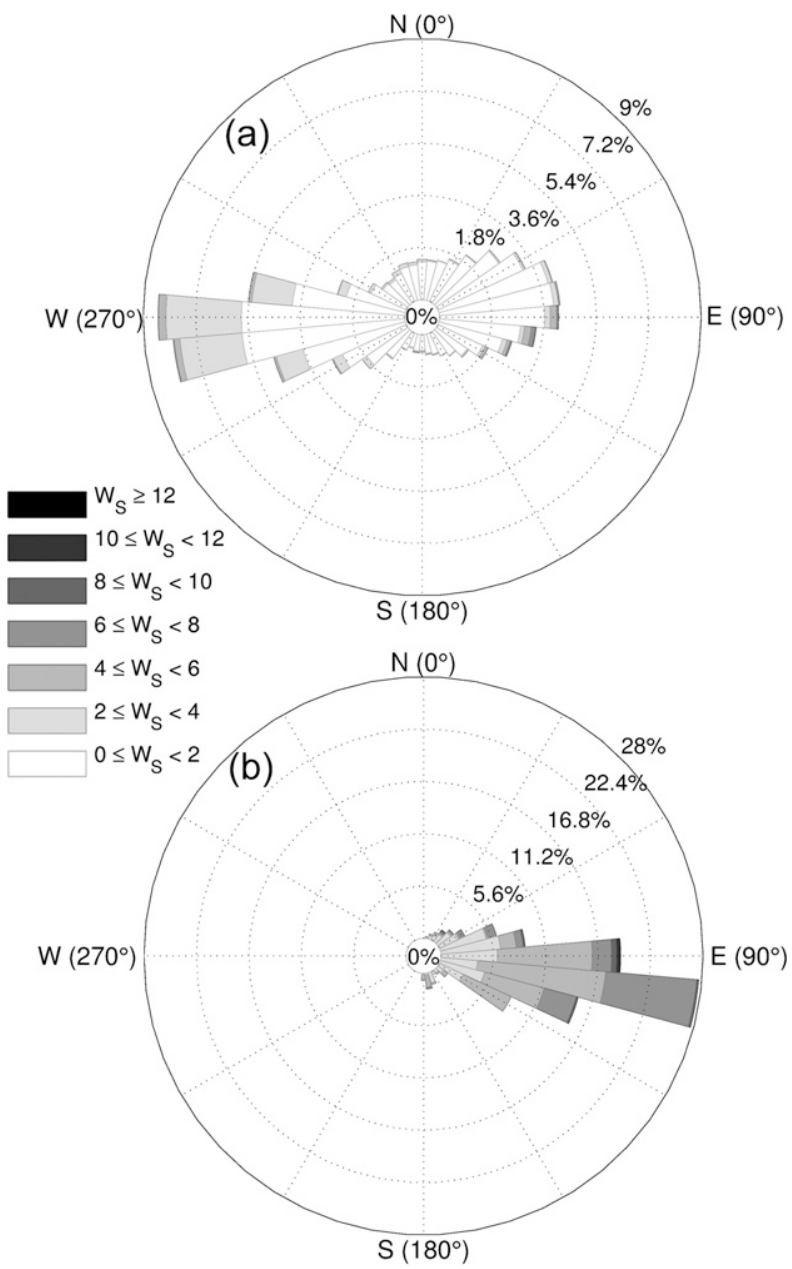

FIG. 4. Wind rose depicting wind speed $W_{S}\left(\mathrm{~m} \mathrm{~s}^{-1}\right)$ and direction frequency at the Vicuña station: (a) for the entire 2004-14 dataset; (b) for TD.

midtropospheric wave-shaped patterns immersed in the midlatitude westerlies. They are characterized by loweramplitude waves and winds with comparatively low speed at 500-hPa level (Figs. 6c,d), although surface features along the coast do not differ significantly from type-A conditions. Type-F conditions represent $12 \%$ of TE (Figs. 6e,f), featuring an easterly zonal wind component at $500 \mathrm{hPa}$. In this case, a deep midtropospheric trough at the east side of the continent presents either a tilted northwest-southeast trough axis elongated and curved over the Andes or a segregation of the equatorward section of the trough as a cutoff low. For surface circulation, Fig. 6 f shows a similar synoptic structure to type A but with a higher spatial extent of high pressure anomalies east of the Andes. This F type, as far as we are aware, has not yet been identified in other studies over the region. Except for the presence/absence of orographic precipitation over the eastern slope of the
Andes, conditions over the western slope are similar to those characterizing zonda events in the lee (eastern) side of the Andes (Norte 2015). Type-B composite represents the remaining $5 \%$ (Figs. $6 \mathrm{~g}, \mathrm{~h}$ ) of TE, within a prefrontal environment during the onset of a cold trough in the mid-to-upper troposphere, with northwest winds at $500 \mathrm{hPa}$ and upper levels. Rutllant and Garreaud (2004) described this type-B condition as the second-most frequent pattern, responsible for $20 \%$ of the raco wind episodes in central Chile. The lower incidence of type-B conditions in TE is not a surprise since prefrontal conditions in austral winter should be more frequent in central Chile than in north-central Chile.

Although type-A conditions correspond to the leading pattern driving terral and raco conditions, the remaining type- $\mathrm{T}$ and type-F patterns could also be regarded as important given their relatively high incidence (30\% of cases) and their capacity to generate strong TE.

\section{b. Winter-chill accumulation}

Winter-chill accumulation, as quantified by the modified Utah (CU) and Dynamic (CP) Models for all 200414 autumn-winter days, is shown in Table 1 . The years 2007 and 2011 were excluded from this analysis because of a large number of missing temperature data $(>10 \%)$. For CU, there was an annual average of $690 \mathrm{CU}$ year $^{-1}$ for the 9-yr period, with a range from a minimum of $276 \mathrm{CU}$ in 2012 to a maximum of $948 \mathrm{CU}$ in 2010, which is indicative of important interannual fluctuations (coefficient of variation $=29 \%$ ). The warm winter of 2012 corresponded to a transition from La Niña to a weak El Niño [the oceanic Niño index (available online at http://www.cpc.ncep.noaa.gov/products/analysis_monitoring/ ensostuff/ensoyears.shtml) $=+0.3^{\circ} \mathrm{C}$ in the JulySeptember trimester], whereas the cold 2010 winter experienced the opposite transition (oceanic Niño index $=-1.1^{\circ} \mathrm{C}$ in the July-September trimester). On the other hand, the average annual value of $\mathrm{CP}$ was 42 , with a range from a minimum of $24 \mathrm{CP}$ in 2012 to a maximum of $59 \mathrm{CP}$ in 2010 (coefficient of variation = $25 \%)$. These values agree in general with those found in previous studies over the same region (Perez et al. 2008). Despite the differences in chill calculation by both approaches (appendixes A and B), the interannual chills estimated by the two models are highly correlated (linear correlation coefficient between annual $\mathrm{CU}$ and $\mathrm{CP}=0.95$ ), but their different rank according to magnitude indicates a differential response to variations in temperature.

Table 1 also separates the CU accumulated only during TD from the remaining days (the non-TD days). This separation was not performed for the case of $\mathrm{CP}$, 

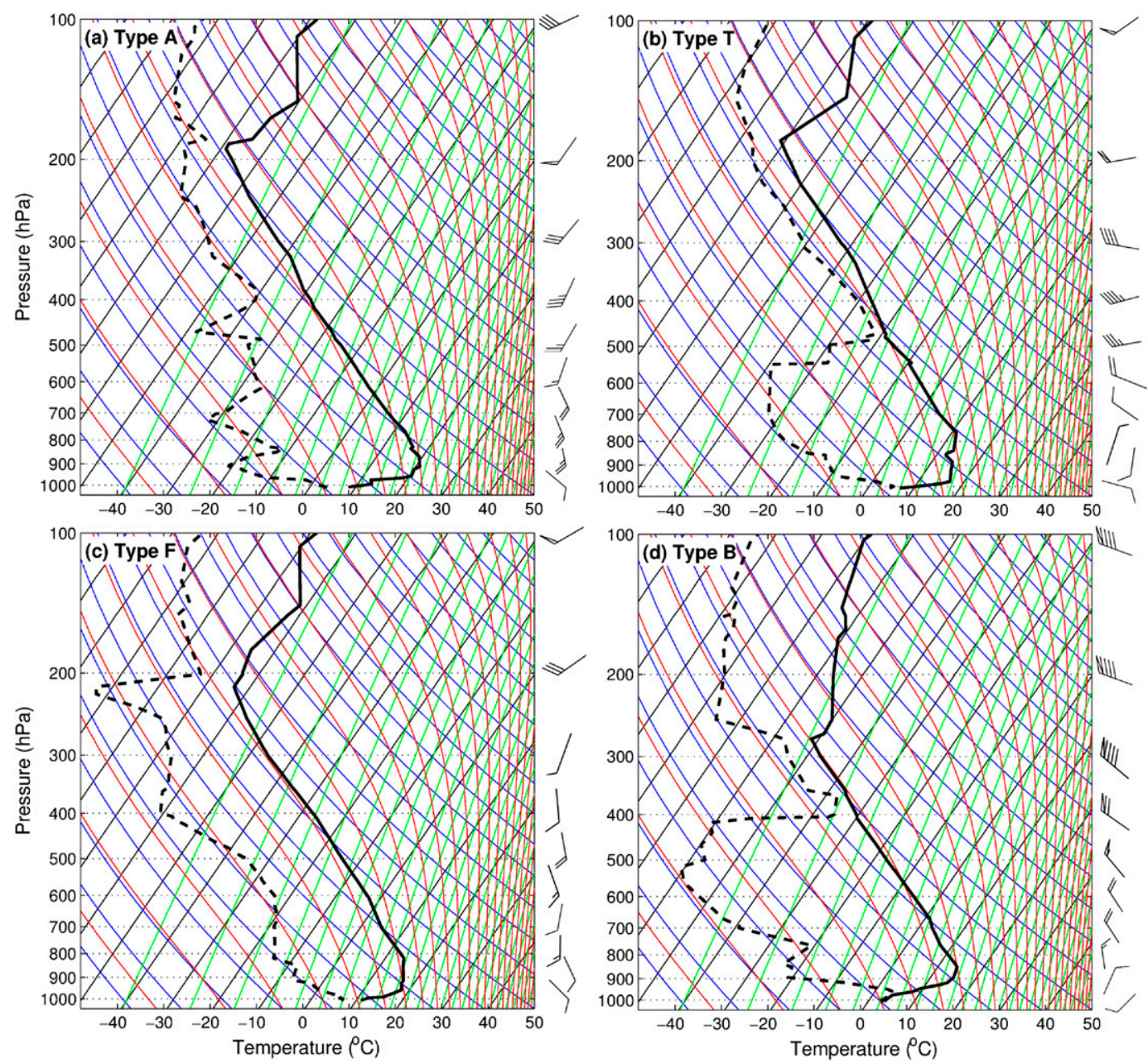

FIG. 5. 1200 UTC skew $T-\log p$ diagrams from the Santo Domingo radiosonde for a representative TE of each synoptic type: (a) $18 \mathrm{Jul} 2014$ (type A), (b) 25 Aug 2009 (type T), (c) 20 Aug 2006 (type F), and (d) 31 Jul 2004 (type B).

since the latter are equal to zero during TD. On an annual basis, and again excluding 2007 and 2011, TD yield a total of $-342 \mathrm{CU}$, with an average of $-5.1 \mathrm{CU}$ per TD. Comparing the mean annual accumulation of $690 \mathrm{CU} \mathrm{yr}^{-1}$ with the annual mean of the negative contribution associated with $\mathrm{TD}\left(-38 \mathrm{CU} \mathrm{yr}^{-1}\right)$, it can be seen that these negative annual contributions correspond to $5.5 \%$ of the mean $\mathrm{CU}$ annual accumulation, suggesting therefore an associated winter-chill loss during TD that does not seem to significantly compromise the onset of budburst in most deciduous fruit trees. Optimal budburst synchronization could, however, be affected in years in which TD concentrate in the colder period (July and August), which coincides with the beginning of dormancy release (Perez et al. 2007).

The statistical relationship between chill accumulation and synoptic configurations that drive terral conditions (section 3a) was investigated by considering the $\mathrm{CU}$ and the thermally labile precursor $x$ of the dormancybreaking factor $y$ [Eq. (B1)] for each synoptic type and terral intensity (Table 2). Table 2 also shows the percentage of TD corresponding to the three terral intensities. Moderate TD driven by type-A configuration is the most frequent case, accounting for $46.5 \%$ of TD, followed by strong TD of type A and moderate TD of type T. Conversely, weak TD are the least frequent, accounting for $7 \%$ of total TD. On average, subtracted CU during TD follow the expected pattern according to intensity, which is reversed only in the case of type-A configuration, in which moderate appears as subtracting a larger number of CU. For $x$ values, no clear tendency in average conditions as in the case of CU is observed, since moderate and strong TD are very similar. These values are well below the average for non-TD $(x=0.65)$, however. 


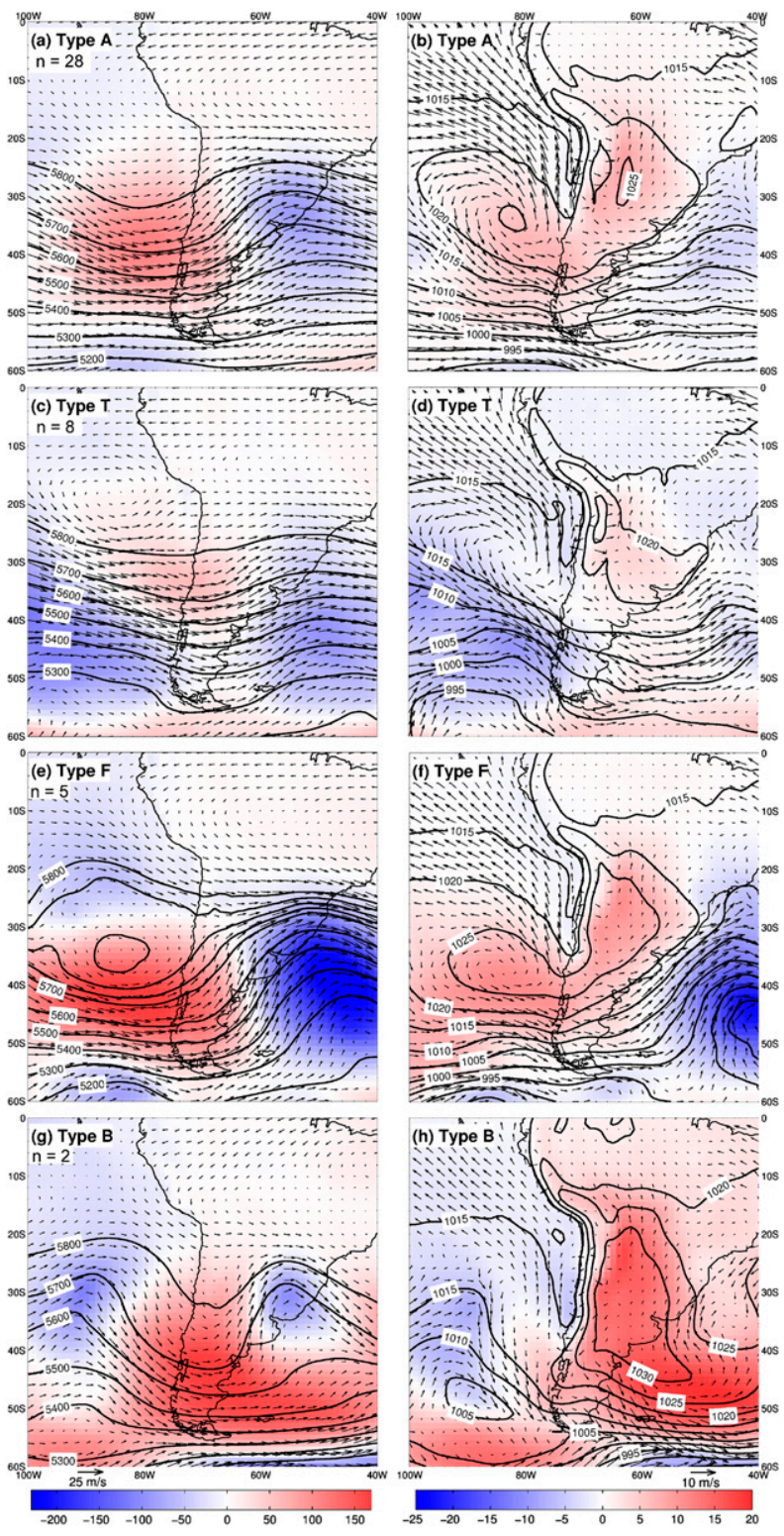

FIG. 6. Composites of (a),(c),(e),(g) 500-hPa geopotential height (gpm; black contours), their anomalies (gpm; colors), and 500-hPa wind vectors and (b),(d),(f),(h) sea level pressure (hPa; black contours), their anomalies (hPa; colors), and $10-\mathrm{m}$ wind vectors for the four TE synoptic types. The corresponding color scale and reference wind vector are shown at the bottom.

Time series of wintertime chill accumulation (CU and $\mathrm{CP}$ ) along with TD occurrences and monthly temperature anomalies are presented in Fig. 7. First, it is clear from the shape of the curves that, despite a certain degree of agreement, the assessment of impacts of warm temperatures associated with TD on chill accumulation will depend on the model used: the accumulation rate can be very similar in some years (e.g., 2013) whereas the divergence is evident for other years, such as was observed for 2012. Nonetheless, Fig. 7 clearly shows the interruption in the seasonal course of chill accumulation during TD, experiencing a reduction in the case of $\mathrm{CU}$ and stabilization in the case of $\mathrm{CP}(\partial \mathrm{CP} / \partial t=0)$, such as those occurring by the end of July in 2004 (Fig. 7a) and in August of 2008 (Fig. 7d). It is worthwhile stressing that both the Dynamic Model and the modified Utah Model have optimal chilling-temperature ranges so that a slight increase in air temperature can in turn induce a slowdown in chill accumulation rate when temperatures drop into suboptimal values, but they are low enough that the chill-accumulation process continues to occur.

Although the reduction in chill accumulation associated with TD is not expected to correlate well with the total annual amounts, a robust relationship with mean monthly temperature anomalies is in evidence, particularly in years of minimum (2012; Fig. $7 \mathrm{~g}$ ) and maximum (2010; Fig. 7f) accumulation, which, in turn, correspond to years of higher and lower winter temperature anomalies, respectively. Thus, Fig. 7 shows progressive seasonal accumulations of $\mathrm{CU}$ and $\mathrm{CP}$ that tend to be similar in early winter, diverging thereafter. For these two extreme years, although absolute winter-chill subtractions associated with TD are very similar $(-31$ and $-30 \mathrm{CU}$ in 2010 and 2012, respectively), their negative relative contributions are $3.3 \%$ and $10.9 \%$ in 2010 and 2012, respectively. The latter is indicative that, while there is a strong relationship between total chill accumulation and winter temperatures [correlation coefficient between CU (CP) and average winter temperature of $-0.91(-0.95)]$, subtracted chill can be regarded as independent of seasonal climate. In addition, although warm winds during TD would not significantly compromise the accumulation of winter chill quantified by $\mathrm{CU}$ during close-to-normal temperature conditions, this negative contribution may become relevant in the seasonal chill balance in years in which positive winter temperature anomalies are present, such as in El Niño years, or for transitional conditions such as in 2012 (Garreaud 2009). Conversely, years of lowerthan-normal temperatures can ensure sufficient chill accumulations such that the effect of TD is irrelevant. Furthermore, this percent decrease in chill accumulation is within the range of observed and future projected trends in CU and CP under scenarios of climate change, as in California (Luedeling et al. 2009b) and Australia (Darbyshire et al. 2011). This, in turn, suggests that, despite the present adaptation of local agriculture to perturbations caused by terral-like phenomena, their influence on winter-chill accumulation might grow steadily with the expected positive trend in inland temperatures for north-central Chile (e.g., Falvey and Garreaud 2009). Thus, expected warmer winters and 
TABLE 1. Accumulated CU and CP during the 2004-14 winter months. The CU accumulated during TD and non-TD are also presented. The years 2007 and 2011 were excluded because of the high number of missing data; SD is the standard deviation of the annual winter accumulations.

\begin{tabular}{lrrrrrrrrrr}
\hline \hline & 2004 & 2005 & 2006 & 2008 & 2009 & 2010 & 2012 & 2013 & 2014 & Mean (SD) \\
\hline CU total & 696 & 591 & 539 & 798 & 700 & 948 & 276 & 844 & 819 & $690(201)$ \\
CU non-TD & 762 & 609 & 564 & 858 & 729 & 979 & 306 & 884 & 862 & $728(207)$ \\
CU TD & -66 & -18 & -25 & -60 & -29 & -31 & -30 & -40 & -43 & $-38(16)$ \\
CP & -43 & -38 & -31 & -49 & -39 & -59 & -24 & -45 & -47 & $-42(10)$ \\
\hline
\end{tabular}

enhanced negation effects of temperature could eventually bring chill accumulation below thresholds for present cultivars in which the chill models fit their physiological response to warmer temperatures during dormancy. Because current chill models mostly rely on empirical relationships, however, uncertainties arise when considering that their suitability changes for cultivars and species growing in different environments. For example, a more accurate description of breaking dormancy was provided by the Dynamic Model than by the Utah Model for apricot growing in Spain and South Africa (Campoy et al. 2012), pistachio trees in Tunisia (Elloumi et al. 2013) and Australia (Zhang and Taylor 2011), and nectarine and peach in Argentina (Maulión et al. 2014), whereas no significant differences in apricot (Ruiz et al. 2007) and sweet cherry (Alburquerque et al. 2008) cultivars growing in a Mediterranean climate in Spain were found. Such differences highlight the need for multimodel assessments of local representativeness of chill models (e.g., Darbyshire et al. 2011). Moreover, projections in chill decline due to increasing temperatures have to be handled with care because of differences in model sensitivities to changing temperatures. In this sense, Darbyshire et al. (2013) reported that the Dynamic Model is less sensitive to the higher temperatures projected for Australia than is the modified Utah Model. Similar results were obtained by Luedeling et al. (2009b) by comparing the Dynamic Model with the classic Utah Model in California. Overall, these authors point to the Dynamic Model as the more suitable in its mathematical structure to assess the influence of higher temperatures on chill accumulation because it includes not only the negative effect of higher temperatures, as the modified Utah Model does, but also the influence of moderate temperatures and their cycle length on chill accumulation. Model evaluation in terms of explained budburst as a function of air temperature is subject to local validation against phenological observations in different cultivars.

\section{Conclusions}

Despite restrictions imposed by water scarcity, agriculture in the Elqui Valley is carried out as a result of use of appropriate technologies and climate suitability for fruit growing and viticulture, among other crops. Chill amounts for bud breaking for deciduous trees may not be guaranteed, however, because of mild winter temperatures, especially during warm winters. In this work, a foehnlike wind locally known as terral de Vicuña was characterized first by examining local meteorological features from a weather station located in Vicuna, together with composites of its synoptic-scale atmospheric forcing, and second by looking at the agricultural impacts in terms of chill accumulation ( $\mathrm{CU}$ and $\mathrm{CP}$ ). The dataset and criteria used for identifying terral days led to a total of $67 \mathrm{TD}$ within 11 winter periods, whose duration (terral hours) frequency distribution allowed them to be classified into events of weak, moderate, or strong intensity. Regardless of their intensity, the overall TD local surface meteorological features show a sharp increase in easterly (downslope) wind speed from the onset of the event and an associated abrupt nocturnal increase in temperature and air drying that extends until dawn and early morning as a result of the strong advection and mixing of adiabatically warmed dry air over the Elqui Valley and its surroundings.

According to the analysis of characteristic synoptic-scale circulation associated with moderate-intensity and strongintensity TE, four dominant circulation patterns emerge,

TABLE 2. Percentage of TD (total), CU (total), and $x$ values (mean) according to TD intensities and synoptic configuration. Here, nTD is the number of TD.

\begin{tabular}{lrrrrr}
\hline \hline & A & \multicolumn{1}{c}{ T } & F & B & Total or mean \\
\hline \multicolumn{7}{c}{ Percent of TD } \\
Weak & 2.3 & 4.7 & 0 & 0 & 7 \\
Moderate & 46.5 & 11.6 & 4.7 & 4.7 & 67 \\
Strong & 11.6 & 7.0 & 4.7 & 2.3 & 26 \\
Weak & -0.8 & -2.5 & 0 & 0 & -1.9 \\
Moderate & -5.7 & -6.2 & -2.2 & -8.3 & -5.6 \\
Strong & -4.1 & -11.0 & -7.8 & -10.5 & -6.3 \\
Weak & 0.81 & 0.42 & 0 & 0 & 0.62 \\
Moderate & 0.46 & 0.45 & 0.30 & 0.45 & 0.42 \\
Strong & 0.42 & 0.36 & 0.39 & 0.48 & 0.41 \\
\hline
\end{tabular}



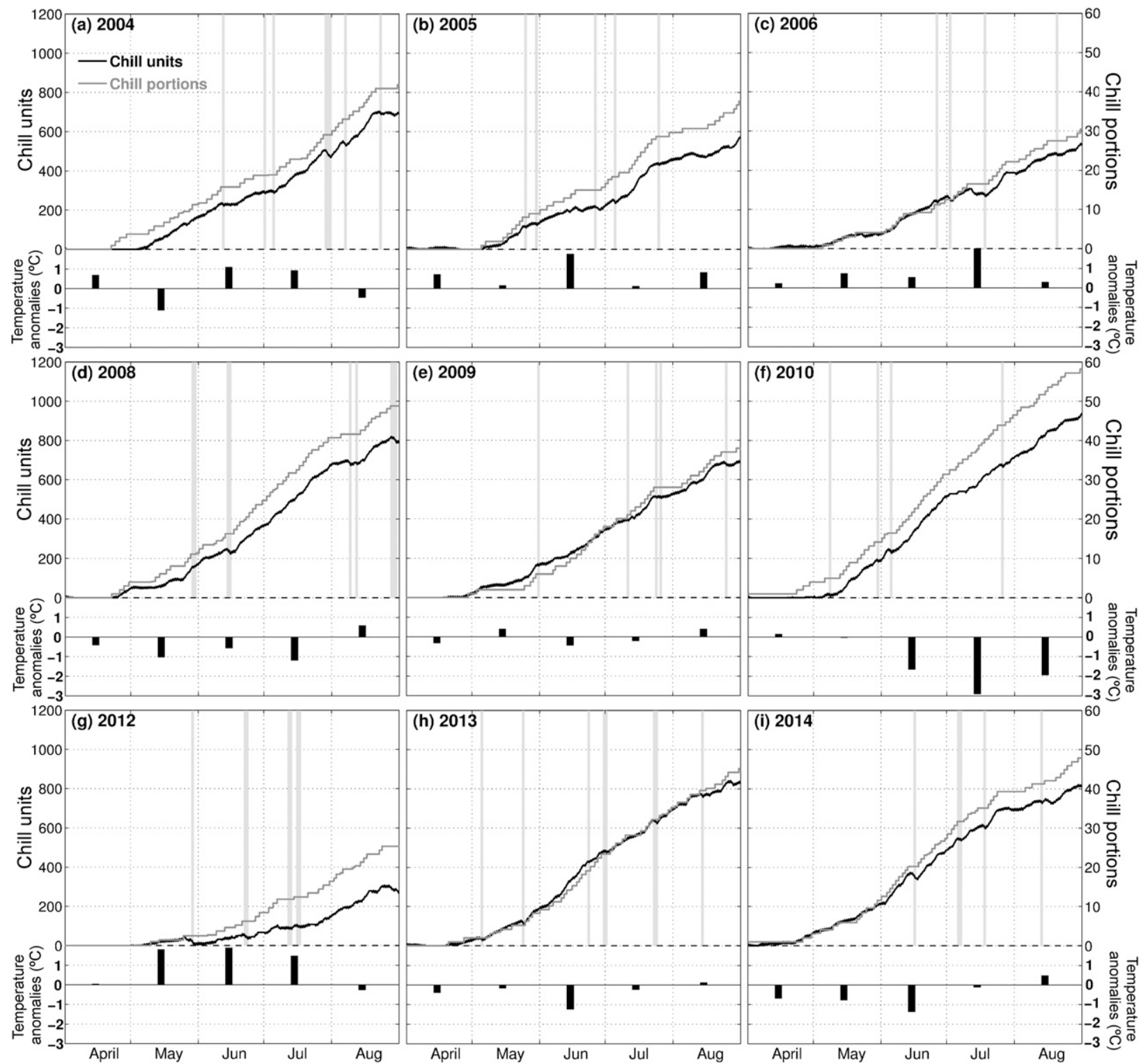

FIG. 7. Cumulative CU (modified Utah Model) and CP (Dynamic Model) from April to August for different years. Gray shaded bars correspond to TD. The black bars at the bottom of each panel show the monthly temperature anomalies.

driving a surface-based layer of easterly wind components that do not necessarily extend into the midtroposphere. For the study period, $65 \%$ of intense TE (type A) are associated with a previously described structure driving the majority of the raco wind events in central Chile (Rutllant and Garreaud 2004). This weather pattern corresponds to a $500-\mathrm{hPa}$ southwest flow driven by an incoming ridge over central Chile, triggering terral conditions. For the remaining $35 \%$ of $\mathrm{TE}, 18 \%$ correspond to a transition condition (type $\mathrm{T}$ ) between type-A and type-B synoptic weather patterns. Foehnlike conditions that result from an easterly midtropospheric zonal flow over the Andes appear after the development of a northwest-southeasttilted deep trough crossing the Andes are responsible for $12 \%$ of TE (type F). Less important, 500-hPa northwest winds generated by an incoming trough just west of the continent characterize the remaining 5\% (type B).

With regard to winter-chill accumulation (CU and $\mathrm{CP}$ ), results suggest that the relevance of chill subtraction as negative $\mathrm{CU}$ and stationary $\mathrm{CP}$ under warmer conditions induced by TE strongly depends on the seasonal climatic context. On average, this negative impact does not seem to compromise the onset of budburst of most deciduous fruit crops within the study period when it comes to the air 
temperature component, with an average of $5.5 \%$ of subtracted CU and an apparent nonsignificant number of hours of no CP accumulation, as compared with the remaining (nonterral) days. Furthermore, this low relative importance of TE in chill accumulation would be minimized during years of anomalous low winter temperatures, since such seasonal condition could ensure the fulfillment of chilling requirements. Conversely, and more important from the point of view of climate hazards, warm winters are associated with a higher impact of TE given the background seasonal low chill accumulation. The latter becomes relevant when considering the dominant mechanisms of interannual-todecadal temperature variability (e.g., El Niño-Southern Oscillation or the Pacific decadal oscillation), together with the observed and projected inland warming trends over the region (Falvey and Garreaud 2009). In this way, a first step in agriculture would be not only a more widespread use of dormancy-breaking chemicals in deciduous fruit trees as a consequence of the chill loss, but a further adaptation in terms of varieties and species that demand less winter chill.

It is certain that a further exploration of the abovementioned meteorological aspects of the terral wind and its impacts on local agriculture requires larger datasets to assess actual trends and the spatial distribution of terral impacts within the valley. With regard to chill accumulation, questions arise in terms of how plants respond to thermal perturbations induced by local events such as the terral under a changing climate. This imposes the need for studies on chilling requirements to break dormancy by species and varieties grown in the Elqui Valley and for model evaluation to elucidate adaptation strategies to a reduced chill availability.

Although outside the scope of this work, the assessment of other effects induced by TE is still pending. Examples of such effects include flower drying and frost damage after the blooming acceleration by higher temperatures during late winter as pointed out in the case of the zonda wind at the lee side of the Andes (Norte 2015). Moreover, agriculture along the Elqui Valley could be affected by the enhancement in winddriven transport of plant diseases and invasive weeds during terral episodes (Gliessman 1998), which in turn could become relevant when it comes to patterns of pollen dispersal and deposition of native species and their spatial distribution along the valley. If palliative actions to prevent damage from these and other possible impacts of TE were to be addressed, forecasting the described weather patterns a few days ahead of their occurrence, together with the long-term characterization of their behavior under a changing climate, could become even more important.
Acknowledgments. The authors are grateful to INIA Intihuasi and CEAZA for the surface meteorological data and to the National Center for Atmospheric Research Computational and Information Systems Laboratory for providing the FNL reanalysis data. Author C. Montes acknowledges the NASA Postdoctoral Program and Oak Ridge Associated Universities. Comments and suggestions from three anonymous reviewers are highly appreciated.

\section{APPENDIX A}

\section{The Modified Utah Model}

One of the most widely used methods to determine winter-chill accumulation and requirements in deciduous species corresponds to the Utah Model of Richardson et al. (1974). Under the assumption that chilling effect varies with temperature, this model transfers subdaily (e.g., hourly) air temperature into CU by weighting different temperature ranges and accounting for negative chill accumulation during high-temperature exposure. In this work, the modified version of the Utah Model proposed by Linvill (1990) was used, which, for an hourly temperature $T$ time series of $n$ hours (hour is denoted by $h$ ), estimates $\mathrm{CU}$ from temperature following a sinusoidal shape between two cutoff points at $0^{\circ}$ and $21^{\circ} \mathrm{C}$ instead of the original step function by

$$
\begin{aligned}
& \mathrm{CU}_{\text {cum }}=\sum_{h=1}^{n} \mathrm{CU}, \\
& \text { with }\left\{\begin{array}{lll}
\mathrm{CU}=0 & \text { if } & T \leq 0^{\circ} \mathrm{C} \\
\mathrm{CU}=\sin \left(\frac{2 \pi T}{28}\right) & \text { if } & 0^{\circ}<T \leq 21^{\circ} \mathrm{C}, \\
\mathrm{CU}=-1 & \text { if } & T>21^{\circ} \mathrm{C}
\end{array}\right.
\end{aligned}
$$

which implies that positive $(\leq 1) \mathrm{CU}$ are assigned between $0^{\circ}$ and $14^{\circ} \mathrm{C}$ [range in which $\sin (2 \pi / 28) \geq 0$; peak $\mathrm{CU}$ at $\left.7^{\circ} \mathrm{C}\right]$ and that the negative contribution $(\mathrm{CU}>-1)$ occurs when $21^{\circ}>T>14^{\circ} \mathrm{C}$.

\section{APPENDIX B}

\section{The Dynamic Model}

The procedure to estimate $\mathrm{CP}$ with the Dynamic Model is based on the following set of equations, here using the notation adopted by several authors, namely in Luedeling et al. (2009a) and Darbyshire et al. (2011).

First, the synthesis of the precursor $x$ of a dormancybreaking factor $y$ is calculated by 


$$
x=x_{s}-\left(x_{s}-y\right) \exp \left(-a k_{1}\right)
$$

where $x_{s}$ is the steady-state value of $x$ and is defined as a function of $T$ :

$$
x_{s}=\left(a_{0} / a_{1}\right) \exp \left[\left(e_{1}-e_{0}\right) / T\right],
$$

with the term $a k_{1}$ in Eq. (B1) being equal to $a_{1} \exp \left(-e_{1} / T\right)$, $T$ being the temperature $(\mathrm{K}), e_{0}$ and $e_{1}$ being the energies of activation for the processes of formation and destruction of $x$, respectively, and $a_{0}$ and $a_{1}$ being their respective rate coefficients. The dormancy-breaking factor $y$ is obtained from the precursor $x$ for each time step $t$, starting at time $t_{0}$, using the following rule:

$$
y= \begin{cases}0 & \text { if } t=t_{0} \\ x_{t-1} & \text { if } t>t_{0} \wedge x_{t-1}<1 . \\ x_{t-1}\left(1-x_{i}\right) & \text { if } t>t_{0} \wedge x_{t-1} \geq 1\end{cases}
$$

As explained in Fishman et al. (1987b), the relationship of Eq. (B3) implies that after $x$ reaches a critical value equal to unity it is transferred to the fixed state $y$, and the process starts again from $x=x\left(1-x_{i}\right)$, with $x_{i}$ defined as the probability of transition between $x$ and $y$, considered as dependent on temperature:

$x_{i}=\frac{\exp \{\operatorname{slp} \times \text { tetmlt } \times[(T-\text { tetmlt }) / T]\}}{1+\exp \{\operatorname{slp} \times \text { tetmlt } \times[(T-\text { tetmlt }) / T]\}}$.

Here slp and tetmlt are thermodynamic constants that take the values 1.6 and $277 \mathrm{~K}$, respectively.

Last, CP are obtained for each hourly time step $t$ from a $\Delta$ variable as

$$
\mathrm{CP}_{t}=\left\{\begin{array}{lll}
\Delta & \text { if } & t=t_{0} \\
\Delta+\mathrm{CP}_{t-1} & \text { if } & t \geq t_{0}
\end{array},\right.
$$

where

$$
\Delta=\left\{\begin{array}{lll}
0 & \text { if } & t=t_{0} \\
0 & \text { if } & t>t_{0} \wedge x<1 \\
x_{i} \times x & \text { if } & t>t_{0} \wedge x \geq 1
\end{array}\right.
$$

Although Fishman et al. (1987a,b) suggest that theoretical parameters of Eqs. (B1) and (B2) should be retrieved from local experiments and for each species and variety, in this work they were set from widely used values: $a_{0}=139.5, a_{1}=$ $2.567 \times 10^{18}, e_{0}=4153.5$, and $e_{1}=12888.8$.

\section{REFERENCES}

Alburquerque, N., F. García-Montiel, A. Carrillo, and L. Burgos, 2008: Chilling and heat requirements of sweet cherry cultivars and the relationship between altitude and the probability of satisfying the chill requirements. Environ. Exp. Bot., 64, 162170, doi:10.1016/j.envexpbot.2008.01.003.
Antico, P. L., S. C. Chou, and C. Mourão, 2016: Zonda downslope winds in the central Andes of South America in a 20-year climate simulation with the Eta Model. Theor. Appl. Climatol., doi:10.1007/s00704-015-1709-2, in press.

Atkinson, C. J., R. M. Brennan, and H. G. Jones, 2013: Declining chilling and its impacts on temperate perennial crops. Environ. Exp. Bot., 91, 48-62, doi:10.1016/j.envexpbot.2013.02.004.

Brinkmann, W. A. R., 1974: Strong downslope winds at Boulder, Colorado. Mon. Wea. Rev., 102, 592-602, doi:10.1175/ 1520-0493(1974)102<0592:SDWABC>2.0.CO;2.

Campoy, J. A., D. Ruiz, and J. Egea, 2011: Dormancy in temperate fruit trees in a global warming context: A review. Sci. Hortic., 130, 357-372, doi:10.1016/j.scienta.2011.07.011.

, L. Allderman, N. Cook, and J. Egea, 2012: The fulfilment of chilling requirements and the adaptation of apricot (Prunus armeniaca L.) in warm winter climates: An approach in Murcia (Spain) and the Western Cape (South Africa). Eur. J. Agron., 37, 43-55, doi:10.1016/j.eja.2011.10.004.

Cao, Y., and R. G. Fovell, 2015: Downslope windstorms of San Diego County. Part I: A case study. Mon. Wea. Rev., 144, 529552, doi:10.1175/MWR-D-15-0147.1.

Caretta, A., A. Ortega, and A. Ortíz Maldonado, 2004: Probabilidades de daño por por viento Zonda en la floración de frutales, vid y olivos, Mendoza, Argentina (probability of damage to vine, fruit, and olive tree blossoms by the zonda wind, Mendoza, Argentina). Rev. Fac. Cienc. Agrar. Univ. Nac. Cuyo, 36, 49-58. [Available online at http://bdigital.uncu. edu.ar/objetos_digitales/82/CarettaAgrarias2-04.pdf.]

Cesaraccio, C., D. Spano, R. L. Snyder, and P. Duce, 2004: Chilling and forcing model to predict bud-burst of crop and forest species. Agric. For. Meteor., 126, 1-13, doi:10.1016/j.agrformet.2004.03.002.

Charrier, G., M. Bonhomme, A. Lacointe, and T. Améglio, 2011: Are budburst dates, dormancy and cold acclimation in walnut trees (Juglans regia L.) under mainly genotypic or environmental control? Int. J. Biometeor., 55, 763-774, doi:10.1007/ s00484-011-0470-1.

Darbyshire, R., L. Webb, I. Goodwin, and S. Barlow, 2011: Winter chilling trends for deciduous fruit trees in Australia. Agric. For. Meteor., 151, 1074-1085, doi:10.1016/j.agrformet.2011.03.010.

,,--- , and,- 2013 : Impact of future warming on winter chilling in Australia. Int. J. Biometeor., 57, 355-366, doi:10.1007/s00484-012-0558-2.

Elloumi, O., M. Ghrab, H. Kessentini, and M. B. Mimoun, 2013: Chilling accumulation effects on performance of pistachio trees cv. Mateur in dry and warm area climate. Sci. Hortic., 159, 80-87, doi:10.1016/j.scienta.2013.05.004.

Erez, A., S. Fishman, G. C. Linsley-Noakes, and P. Allan, 1990: The dynamic model for rest completion in peach buds. Acta Hortic., 276, 165-174, doi:10.17660/ActaHortic.1990.276.18.

Falvey, M., and R. Garreaud, 2007: Wintertime precipitation episodes in central Chile: Associated meteorological conditions and orographic influences. J. Hydrometeor., 8, 171-193, doi:10.1175/JHM562.1.

- and — 2009: Regional cooling in a warming world: Recent temperature trends in the southeast Pacific and along the west coast of subtropical South America (1979-2006). J. Geophys. Res., 114, D04102, doi:10.1029/2008JD010519.

Fishman, S., A. Erez, and G. A. Couvillon, 1987a: The temperature dependence of dormancy breaking in plants: Mathematical analysis of a two-step model involving cooperative transition. J. Theor. Biol., 124, 473-483, doi:10.1016/S0022-5193(87)80221-7. - —, and $-1987 \mathrm{~b}$ : The temperature dependence of dormancy breaking in plants: Computer simulation of 
processes studied under controlled temperatures. J. Theor. Biol., 126, 309-321, doi:10.1016/S0022-5193(87)80237-0.

Garreaud, R., 2009: The Andes climate and weather. Adv. Geosci., 22, 3-11. [Available online at http://adv-geosci.net/22/3/2009/ adgeo-22-3-2009.pdf.]

- , and P. Aceituno, 2007: Atmospheric circulation and climatic variability. The Physical Geography of South America, T. Veblen, K. Young, and A. Orme, Eds., Oxford University Press, 45-59.

_ J. Rutllant, and H. Fuenzalida, 2002: Coastal lows in north-central Chile: Mean structure and evolution. Mon. Wea. Rev., 130, 75-88, doi:10.1175/1520-0493(2002)130<0075:CLATSW>2.0.CO;2.

Ghrab, M., M. B. Mimoun, M. M. Masmoudi, and N. B. Mechlia, 2014: Chilling trends in a warm production area and their impact on flowering and fruiting of peach trees. Sci. Hortic., 178, 87-94, doi:10.1016/j.scienta.2014.08.008.

Gliessman, S. R., 1998: Agroecology: Ecological Processes in Sustainable Agriculture. CRC Press, 384 pp.

Hennessy, K., and K. Clayton-Greene, 1995: Greenhouse warming and vernalisation of high-chill fruit in southern Australia. Climatic Change, 30, 327-348, doi:10.1007/BF01091930.

Inzunza, J., 2009: Relación entre el viento puelche y la ocurrencia de incendios forestales en la región del Bío Bío, Chile (The relation between the puelche wind and the occurrence of forest fires in the Bío Bío region, Chile). Ing. Cienc., 5, 33-48. [Available online at http://publicaciones.eafit.edu.co/index. php/ingciencia/article/viewFile/54/52.]

Juliá, C., D. A. Rahn, and J. A. Rutllant, 2012: Assessing the influence of the $\mathrm{MJO}$ on strong precipitation events in subtropical, semi-arid north-central Chile $\left(30^{\circ} \mathrm{S}\right)$. J. Climate, 25, 7003-7013, doi:10.1175/JCLI-D-11-00679.1.

Kalthoff, N., and Coauthors, 2002: Mesoscale wind regimes in Chile at $30^{\circ}$ S. J. Appl. Meteor., 41, 953-970, doi:10.1175/ 1520-0450(2002)041<0953:MWRICA > 2.0.CO;2.

—, M. Fiebig-Wittmaack, C. Meißner, M. Kohler, M. Uriarte, I. Bischoff-Gauß, and E. González, 2006: The energy balance, evapotranspiration and nocturnal dew deposition of an arid valley in the Andes. J. Arid Environ., 65, 420-443, doi:10.1016/ j.jaridenv.2005.08.013.

Linsley-Noakes, G. C., and P. Allan, 1994: Comparison of two models for the prediction of rest completion in peaches. Sci. Hortic., 59, 107-113, doi:10.1016/0304-4238(94)90077-9.

Linvill, D. E., 1990: Calculating chilling hours and chill units from daily maximum and minimum temperature observations. HortScience, 25, 14-16. [Available online at http://hortsci. ashspublications.org/content/25/1/14.full.pdf.]

Luedeling, E., 2012: Climate change impacts on winter chill for temperate fruit and nut production: A review. Sci. Hortic., 144, 218-229, doi:10.1016/j.scienta.2012.07.011.

_ - M. Zhang, M. McGranahan, and C. Leslie, 2009a: Validation of winter chill models using historic records of walnut phenology. Agric. For. Meteor., 149, 1854-1864, doi:10.1016/j.agrformet.2009.06.013.

,,,--- and,$- 2009 \mathrm{~b}$ : Sensitivity of winter chill models for fruit and nut trees to climatic changes expected in California's Central Valley. Agric. Ecosyst. Environ., 133, 23-31, doi:10.1016/j.agee.2009.04.016.

Maulión, E., G. H. Valentini, L. Kovalevski, M. Prunello, L. L. Monti, M. E. Daorden, M. Quaglino, and G. D. L. Cervigni, 2014: Comparison of methods for estimation of chilling and heat requirements of nectarine and peach genotypes for flowering. Sci. Hortic., 177, 112-117, doi:10.1016/j.scienta.2014.07.042.

Miller, A., 1976: The climate of Chile. Climates of Central and South America, W. Schwerdtfeger, Ed., World Survey of Climatology, Vol. 12, Elsevier Scientific, 113-145.
Miranda, C., L. G. Santesteban, and J. B. Royo, 2013: Evaluation and fitting of models for determining peach phenological stages at a regional scale. Agric. For. Meteor., 178-179, 129139, doi:10.1016/j.agrformet.2013.04.016.

Montecinos, A., and P. Aceituno, 2003: Seasonality of the ENSOrelated rainfall variability in central Chile and associated circulation anomalies. J. Climate, 16, 281-296, doi:10.1175/ 1520-0442(2003)016<0281:SOTERR $>2.0 . C O ; 2$.

Montes, C., A. Ibacache, A. Salvatierra, and L. Bascuñán, 2010: Valle de Elqui: Efecto del agroclima sobre frutales de hoja caduca (Elqui Valley: Effect of agroclimate on deciduous fruit). Tierra Adentro, 91, 29-33. [Available online at http:// www2.inia.cl/medios/tierraadentro/TierraAdentro91.pdf.]

— R. C. Muñoz, and J. F. Pérez-Quezada, 2013: Surface atmospheric circulation patterns and associated minimum temperatures in the Maipo and Casablanca valleys, central Chile. Theor. Appl. Climatol., 111, 275-284, doi:10.1007/s00704-012-0663-5.

NOAA/NCEP, 2000: NCEP FNL Operational Model Global Tropospheric Analyses, continuing from July 1999 (updated daily). National Center for Atmospheric Research Computational and Information Systems Laboratory Research Data Archive, doi:10.5065/D6M043C6.

Norte, F., 2015: Understanding and forecasting Zonda wind (Andean foehn) in Argentina: A review. Atmos. Climate Sci., 5, 163-193, doi:10.4236/acs.2015.53012.

Perez, F. J., S. Rubio, and J. Ormeño-Nuñez, 2007: Is erratic bud-break in grapevines grown in warm winter areas related to disturbances in mitochondrial respiratory capacity and oxidative metabolism? Funct. Plant Biol., 34, 624-632, doi:10.1071/FP06272.

_ - J. Ormeño, B. Reynaert, and S. Rubio, 2008: Use of the Dynamic Model for the assessment of winter chilling in a temperate and a subtropical climatic zone of Chile. Chil. J. Agric. Res., 68, 198-206, doi:10.4067/S0718-58392008000200010.

Puccio, E., 1976: El Terral en Vicuña, Chile. Un viento local tipo foehn (The terral de Vicuña, Chile. A foehnlike local wind). Rev. Geofis., 4, 139-154.

Reginato, G., C. Pinilla, and J. L. Camus, 1994: Effects of hydrogen cyanamide plus mineral oil sprays in Vitis vinifera L. cv. Thompson seedless. Agric. Téc., 54, 192-198.

Reid, S., and R. Turner, 1997: Wind storms. Tephra, 16, 24-32.

Richardson, E. A., S. D. Seeley, and D. R. Walker, 1974: A model for estimating the completion of rest for Redhaven and Elberta peach trees. HortScience, 9, 331-332.

Ruiz, D., J. A. Campoy, and J. Egea, 2007: Chilling and heat requirements of apricot cultivars for flowering. Environ. Exp. Bot., 61, 254-263, doi:10.1016/j.envexpbot.2007.06.008.

Rutllant, J., and R. Garreaud, 2004: Episodes of strong flow down the western slope of the subtropical Andes. Mon. Wea. Rev., 132, 611622, doi:10.1175/1520-0493(2004)132<0611:EOSFDT>2.0.CO;2.

Shaltout, A. D., and C. R. Unrath, 1983: Rest completion prediction model for 'Starkrimson delicious' apples. J. Amer. Soc. Hortic. Sci., 108, 957-961.

Weinberger, J. H., 1950: Chilling requirements of peach varieties. Proc. Amer. Soc. Hortic. Sci., 56, 122-128.

Whiteman, C. D., T. Haiden, B. Pospichal, S. Eisenbach, and R. Steinacker, 2004: Minimum temperatures, diurnal temperature ranges, and temperature inversions in limestone sinkholes of different sizes and shapes. J. Appl. Meteor., 43, 1224-1236, doi:10.1175/1520-0450(2004)043<1224:MTDTRA>2.0.CO;2.

Zhang, J., and C. Taylor, 2011: The Dynamic Model provides the best description of the chill process on 'Sirora' pistachio trees in Australia. HortScience, 46, 420-425. [Available online at http://hortsci.ashspublications.org/content/46/3/420.full.pdf.] 